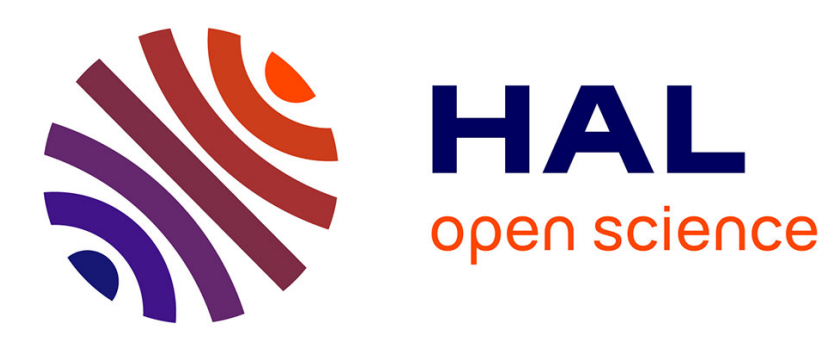

\title{
Examen des possibilités d'éradication du nématode à kystes, Globodera pallida Stone
}

\author{
Didier Mugniery, Catherine Balandras, Madeleine Oger
}

\section{To cite this version:}

Didier Mugniery, Catherine Balandras, Madeleine Oger. Examen des possibilités d'éradication du nématode à kystes, Globodera pallida Stone. Agronomie, 1984, 4 (8), pp.773-778. hal-00884695

\section{HAL Id: hal-00884695 \\ https://hal.science/hal-00884695}

Submitted on 1 Jan 1984

HAL is a multi-disciplinary open access archive for the deposit and dissemination of scientific research documents, whether they are published or not. The documents may come from teaching and research institutions in France or abroad, or from public or private research centers.
L'archive ouverte pluridisciplinaire $\mathbf{H A L}$, est destinée au dépôt et à la diffusion de documents scientifiques de niveau recherche, publiés ou non, émanant des établissements d'enseignement et de recherche français ou étrangers, des laboratoires publics ou privés. 


\title{
Examen des possibilités d'éradication du nématode à kystes, Globodera pallida Stone
}

\author{
Didier MUGNIERY \& Catherine BALANDRAS \\ avec la collaboration technique de Madeleine OGER \\ I.N.R.A., Laboratoire de Zoologie, Centre de Recherches de Rennes, F 35650 Le Rheu
}

RÉSUMÉ

\begin{abstract}
Il ressort d'expérimentations mises en place entre 1979 et 1982, visant l'éradication des nématodes à kystes de la pomme de terre, que l'absence de pomme de terre ne provoque dans l'Ouest de la France qu'une très faible diminution annuelle des populations (18-20 p. 100). Dans ces conditions, étant donné le système agricole local, l'éradication est pratiquement impossible.

A l'inverse, les cultures-pièges de pomme de terre, qui provoquent l'éclosion des kystes, conduisent à des réductions annuelles de l'ordre de 80 p. 100. L'efficacité de la culture-piège peut être encore augmentée par l'adjonction d'un traitement nématicide de contact. Un essai réalisé dans les conditions agricoles classiques, comportant un traitement nématicide de contact et 2 années de culture-piège, conduit à une réduction moyenne de 98,5 p. 100 de la population.
\end{abstract}

Mots clés additionnels : Solanum tuberosum, éradication, lutte chimique, plantes-pièges.

The recent discovery of the potato cyst nematode Globodera pallida in an area of potato seed production emphasized the difficult problem of eradication. From experiments set up in agricultural conditions from 1979, it appeared that the mere absence of a host plant was not effective enough : the yearly population decrease was not more than 18-20\% and the risks of dissemination remained too high for many years.

However, the trap-cropping potato system appeared to be very effective in increasing the speed of disinfestation, with $80 \%$ annual mortality. Application of a contact nematicide such as ethoprophos increased the efficiency of this system : 2 years of trap cropping potato and one nematicide application reduced the nematode population by $98.5 \% ; 21$ years with continuous non-host plants would have given the same result. This control system allows the farmer to cultivate a non-host plant immediately after lifting the trap potatoes and is not expensive because it is possible to sow small cheap tubers instead of normal expensive seed tubers.

Additional key words : Solanum tuberosum, eradication, chemical control, trap-cropping.

\section{INTRODUCTION}

En France, la découverte de nématodes à kystes, Globodera rostochiensis Woll. ou Globodera pallida Stone, en zone de production de plant de pomme de terre, entraîne immédiatement l'interdiction de culture de cette espèce végétale. Le Règlement technique (GNIS, 1978) stipule en effet que la tolérance pour ces nématodes est nulle et l'arrêté ministériel du 10 janvier 1972, modifié par celui du 19 janvier 1973, indique catégoriquement qu'en cas de détection de $G$. rostochiensis ou $G$. pallida, la culture de plant de pomme de terre est rigoureusement interdite, et ceci jusqu'à ce qu'on ne puisse plus, dans la parcelle contaminée, constater la présence des dits parasites.
Cet abandon total de culture de pomme de terre conduit à la longue à une disparition des nématodes ; ceux-ci font en effet preuve d'une spécificité quasi absolue : seules, la pomme de terre et la tomate permettent leur développement. Par conséquent, en l'absence de tels végétaux, les larves éclosent naturellement et meurent sans assurer de descendance. Il s'ensuit une réduction annuelle des populations, estimée à $50 \mathrm{p} .100$ par OOSTENBRINK (1950) et SPEARS (1968), à 35 p. 100 par Den OUDEN (1969), à 33 p. 100 par JONES (1969), à 18-20 p. 100 par STONE et al. (1973). Si l'on admet qu'une population est difficile à détecter en dessous de 0,1 larve/g de sol et si le niveau d'infestation initial est de 50 larves, il faudrait attendre 20 à 30 ans pour atteindre le niveau désiré. Ce calcul est évidemment très arbitraire, mais les 
observations faites par divers auteurs travaillant en zones climatiques analogues à celles de la Bretagne corroborent ce calcul ; GRAINGER (1964) rapporte, en Ecosse, une infestation vieille de 27-28 ans ; en Ulster, Mc KENNA \& WINSLOW (1973) retrouvent, en 1969, une quantité non négligeable de larves viables dans des sols dont la dernière culture de pomme de terre remonte à 1948.

En plus de sa durée, l'inconvénient majeur de ce type de lutte passive est le maintien de zones contaminées : il existe toujours un risque de dissémination important des parasites par l'intermédiaire des machines agricoles, des eaux courantes, etc...

En 1979 et 1980, nous avons éprouvé l'effet de différents moyens de lutte, seuls ou combinés, utilisables dans la pratique agricole dans le but d'obtenir au moindre coût des réductions rapides et fortes des populations en place. Compte tenu des résultats acquis, la méthode qui nous avait semblé la plus rationnelle a été appliquée et éprouvée en 1981-1982 dans une parcelle infestée.

Les essais ont été conduits dans le Finistère sur 2 communes : Guiclan (1979-1980) et Plouzévédé (1981-1982) dans 2 parcelles où la production de plant avait été interdite et donc abandonnée par suite de la présence de nématodes.

\section{II. ÉTUDE COMPARÉE DE PLUSIEURS PROCÉDÉS DE LUTTE}

\section{A. Utilisation de plantes non hôtes}

Cette méthode passive est directement inspirée par la législation interdisant toute culture-hôte. Comme plantes non hôtes, nous avons choisi une culture sarclée, la carotte, et le ray-grass italien, culture type de recouvrement étouffant les repousses de pomme de terre et limitant les risques de dissémination des kystes en raison de l'absence de travail du sol après semis.

Nous avons également utilisé 2 plantes nématicides : le tagète ou ceillet d'Inde, bien que OMIDVAR (1962) ait montré son peu d'efficacité vis-à-vis de G. rostochiensis, et le lupin que TiMOFEEV \& PONIN (1975) estiment responsable de réduction importante de population.

\section{Matériel et méthode}

Des parcelles de $10 \mathrm{~m}^{2}$ sont semées en carotte, raygrass, ou repiquées en tagète au printemps 1979, semées en lupin en 1980. Seules les parcelles ray-grass restent 2 ans consécutifs en place. Pour chaque plante non hôte, les parcelles élémentaires sont distribuées sur le terrain de telle manière que l'on dispose d'une gamme d'infestation aussi étalée que possible.

Un échantillon de terre constitué de 40 prises élémentaires, correspondant environ à un poids de $1,5 \mathrm{~kg}$, est prélevé en mars avant semis, puis en novembre. Le 1/10 de l'échantillon est analysé après homogénéisation dans un appareil dérivé de celui décrit par COOLEN \& d'HERDE (1972). Les kystes sont triés, dénombrés et écrasés pour estimation du contenu. Les résultats sont exprimés en kystes par $100 \mathrm{~g}$ de sol $(\mathrm{K} / 100 \mathrm{~g})$ et en larves viables par $\mathrm{g}$ de sol $(\mathrm{lv} / \mathrm{g})$.

\section{Résultats}

Bien que sans grand intérêt en général en dynamique de populations, le critère $\mathrm{K} / 100 \mathrm{~g}$ est important à considérer ici : ce sont les kystes, en effet, qui disséminent l'espèce et que l'on retrouve à destination lors des litiges aux frontières. Les diminutions des populations de kystes sont très faibles (tabl. 1). Ceci s'explique aisément quand on sait que les kystes vides ou pleins ne sont que très lentement détruits par les organismes du sol, le délai variant selon les sites.

Les chutes de populations des larves sont beaucoup plus intéressantes à considérer. Dans le cas de la carotte et du tagète, ces 2 plantes se sont mal développées en 1979 par suite de la sécheresse de l'été et les taux de diminution ont été respectivement de 28 et 27 p. 100. Pour les cultures de couverture, préservant une bonne humidité du sol et limitant les fortes températures, les diminutions ne dépassent pas 20 p. 100. On remarquera que 2 ans de ray-grass conduisent à une réduction globale de 38 p. 100 , non différente des 36 p. 100 attendus : $(1-0,2)(1-0,2)=0,64=1-0,36$.

\section{Discussion}

Nous retrouvons ici des résultats très voisins de ceux obtenus par ailleurs dans des conditions climatiques voisines (STONE et al., 1973). Si l'on considère que le ray-grass, du fait de travaux du sol très réduits par rapport à ceux d'une culture sarclée ou industrielle, consti-

TABLEAU 1

Effet de diverses cultures non multiplicatrices sur les populations de Globodera pallida Influence of various non-host plants on the multiplication rate of Globodera pallida

\begin{tabular}{|c|c|c|c|c|c|c|c|c|c|}
\hline & \multicolumn{2}{|c|}{$\begin{array}{c}\text { Kystes } / 100 \mathrm{~g} \\
(\mathrm{~K} / 100 \mathrm{~g})\end{array}$} & \multicolumn{2}{|c|}{$\begin{array}{c}\text { Larves viables/g } \\
(\mathrm{lv} / \mathrm{g})\end{array}$} & \multicolumn{2}{|c|}{$\begin{array}{c}\text { Test de Student } \\
\text { t observé }\end{array}$} & \multirow[t]{2}{*}{$\mathrm{ddl}$} & \multicolumn{2}{|c|}{$\begin{array}{c}\text { Taux moyen } \\
\text { de multiplication }\end{array}$} \\
\hline & avant & après & avant & après & $\mathrm{K} / 100 \mathrm{~g}$ & $\mathrm{lv} / \mathrm{g}$ & & en $\mathrm{K} / 100 \mathrm{~g}$ & en $\mathrm{lv} / \mathrm{g}$ \\
\hline Carotte & 287 & 275 & 197 & 145 & 2,101 & 3,631 & 6 & $0,96 \mathrm{NS}$ & $0,72 \mathrm{~S}$ \\
\hline Tagètes & 189 & 188 & 139 & 102 & 0,131 & 2,687 & 6 & $0,99 \mathrm{NS}$ & $0,73 \mathrm{~S}$ \\
\hline Lupin & 214 & 205 & 73 & 58 & 0,879 & 1,701 & 6 & $0,96 \mathrm{NS}$ & $0,80 \mathrm{NS}$ \\
\hline Ray-grass (1 an) & 309 & 304 & 161 & 135 & 0,890 & 2,315 & 8 & $0,98 \mathrm{NS}$ & $0,80 \mathrm{~S}$ \\
\hline Ray-grass ( 2 ans) & 309 & 292 & 161 & 100 & 1,182 & 5,351 & 8 & $0,94 \mathrm{NS}$ & $0,62 \mathrm{HS}$ \\
\hline Pomme de terre piège d'été & & & & & & & & & \\
\hline ( $2^{e}$ culture) & 429 & 410 & 114 & 82 & 0,910 & 2,732 & 11 & $0,96 \mathrm{NS}$ & $0,80 \mathrm{~S}$ \\
\hline
\end{tabular}


tue le type de plante-hôte le plus adéquat pour éviter la dissémination du parasite, force est d'admettre que son effet sur les populations est très faible.

Passer de 50 à $0,1 \mathrm{lv} / \mathrm{g}$ exigerait théoriquement 28 années et, si on admet, comme STELTER (1970) que le pourcentage de diminution est plus élevé à l'issue de la $1^{\text {re }}$ année de culture de plante non hôte que des suivantes, cette durée serait encore plus longue.

\section{B. Utilisation conjointe d'une culture piège de pommes de terre et de traitements nématicides}

Parmi les moyens actifs de lutte utilisables par l'agriculteur, figurent les traitements de sol, l'utilisation des variétés résistantes et la culture de pommes de terre récoltées avant maturité des femelles. L'utilisation de ces moyens correspond en fait aux dérogations prévues par l'arrêté ministériel du 10 janvier 1972, mais pour le seul cas des pommes de terre de consommation.

Nous avons éprouvé l'effet de ces diverses méthodes, seules ou associées, en considérant que :

- en Bretagne, l'utilisation des fumigants ne peut être envisagée qu'exceptionnellement : les températures du sol propices à la fumigation se rencontrent en septembre et, à cette époque, celui-ci porte des cultures. D'autre part, le caractère phytotoxique des fumigants interdit leur utilisation avant plantation. Nous avons donc utilisé l'éthoprophos, produit peu phytotoxique, agissant préférentiellement par contact, et l'oxamyl à action endothérapique.

- l'espèce présente est $G$. pallida race $\mathrm{E}(\mathrm{Pa} 3)$, visà-vis de laquelle n'existent pas de variétés commercialisables résistantes. En comparaison avec le cultivar témoin non résistant "Sirtema », a été utilisé le cultivar « Amalfy », moins favorable au développement de Pa 3 (Mugniery, 1982a).

- le cultivar "Sirtema ", à tubérisation hâtive, récolté précocement, permet d'obtenir à la fois une destruction des stades endoradiculaires avant maturité des femelles et un rendement économique positif (MUGNIERY, 1982b). C'est pourquoi nous l'avons utilisé préférentiellement.

\section{Matériel et méthodes}

La même méthodologie que précédemment est utilisée. Les nématicides sont utilisés en traitement de toute la surface immédiatement avant plantation : éthoprophos à $10 \mathrm{~kg} \mathrm{MA} / \mathrm{ha}$, oxamyl : $6 \mathrm{~kg} \mathrm{MA} / \mathrm{ha}$, seuls ou conjointement.

Pour chaque traitement, les parcelles élémentaires sont réparties sur le terrain de façon à ce que l'on dispose d'une gamme d'infestation semblable et très large.

En 1979, les plantations du cultivar "Sirtema " ont lieu le 19 avril et 2 récoltes, l'une hâtive, l'autre tardive, les 27 juin et 8 août.

Une $2^{\mathrm{e}}$ plantation de « Sirtema » a lieu le 10 août sur les parcelles récoltées le 8 août, dans le but de faire éclore les larves néoformées à la suite de la $1^{\text {re }}$ culture. Le végétal est arraché le 10 septembre pour détruire ces larves avant maturité sexuelle.

En 1980, les 2 cultivars "Sirtema " et "Amalfy " sont plantés le 18 avril. Pour « Sirtema », 2 récoltes, hâtive et tardive, sont effectuées les 16 juin et 23 juillet.
Pour « Amalfy », la récolte est réalisée intégralement le 23 juillet.

\section{Résultats}

Il existe (fig. 1 et 2) une corrélation hautement significative entre le niveau de population initiale en $\mathrm{lv} / \mathrm{g}$ et le taux de multiplication observé, à l'exception du cas de la $2^{\text {e }}$ culture de pomme de terre : les résultats de celle-ci correspondent à une chute moyenne de $28 \mathrm{p}$. $100 \mathrm{du}$ nombre de $\mathrm{lv} / \mathrm{g}$ (tabl. 1), sans changement significatif de la densité des kystes.

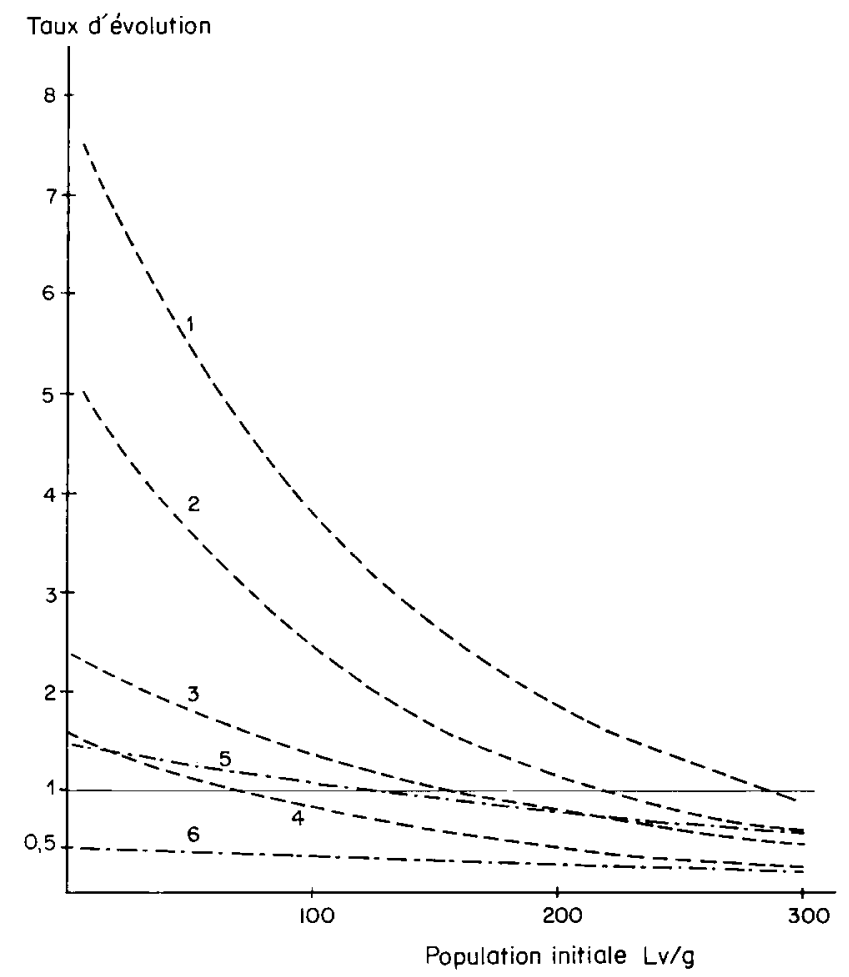

Figure 1

Influence de la date de récolte et des traitements nématicides sur la multiplication de G. pallida en 1979 sur cv "Sirtema ».

Récolte tardive (1), avec éthoprophos (2), avec oxamyl (3), avec éthoprophos et oxamyl (4), récolte précoce (5), avec éthoprophos (6). Ethoprophos: $10 \mathrm{~kg} \mathrm{MA} / \mathrm{ha}$; Oxamyl : $6 \mathrm{~kg} \mathrm{MA} / \mathrm{ha}$.

Effect of lifting time and nematicide applications on the multiplication of G. pallida on potato cv « Sirtema » in 1979.

Dans tous les autres cas, la liaison entre population initiale et taux d'évolution montre qu'il y a eu formation d'une nouvelle génération, dont l'importance varie avec le cultivar de pomme de terre, la durée de végétation, le traitement chimique.

La comparaison (fig. 2) "Amalfy »-«Sirtema » confirme le caractère d'hôte moins favorable d'« Amalfy ». La comparaison (fig. 1 et 2) « Sirtema » arrachage précoce/arrachage tardif confirme l'importance à accorder aux récoltes hâtives pour limiter la formation des femelles néoformées. Enfin, l'effet des nématicides en protection d'une variété récoltée précocement (fig. 1 et 2) ou tardivement (fig. 1) indique l'existence des différences significatives : l'effet oxamyl + éthoprophos est supérieur à l'oxamyl seul, lequel est supérieur à l'éthoprophos seul. Sans traitement chimique, la multiplication est toujours plus intense. 


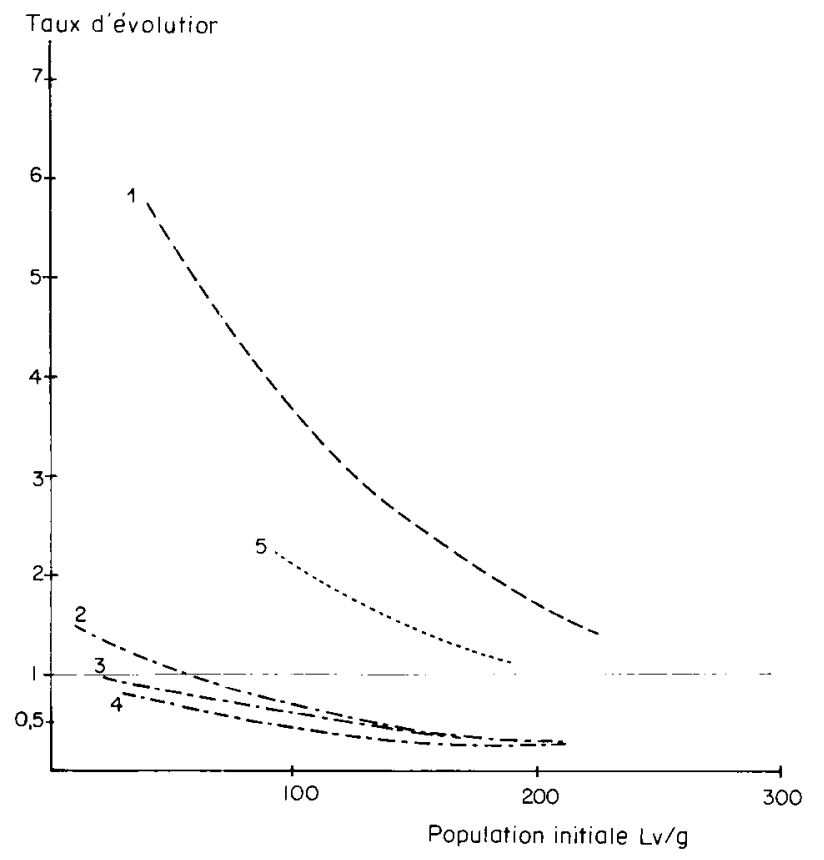

Figure 2

Influence du cultivar et des traitements nématicides sur la multiplication de G. pallida en 1980.

Cultivar « Sirtema » (1), avec éthoprophos (2), avec oxamyl (3), avec ethoprophos et oxamyl (4), cultivar «Amalfy» (5)

Ethoprophos : $10 \mathrm{~kg} \mathrm{MA/ha;}$

Oxamyl : $6 \mathrm{~kg} M A / \mathrm{ha}$.

Effect of cultivar and nematicide applications on the multiplication of G. pallida in 1980.

\section{Discussion}

La culture de la pomme de terre a pour premier effet d'induire l'éclosion des larves dans une proportion de l'ordre de 80 p. 100 (TRIFFITT, 1930). Un traitement de contact détruit les larves dans les kystes et le nombre de larves survivantes, pouvant éclore et se développer, en est d'autant plus réduit. Le traitement endothérapique a surtout comme effet de limiter la pénétration des larves dans les racines (Den OUDEN, 1971). Toute l'efficacité de la lutte repose ensuite sur le type de cultivar et sur sa durée de végétation. Faute de posséder des cultivars résistants, il se confirme qu'un cultivar moyennement favorable aux nématodes en laisse se développer suffisamment pour que le sol se retrouve encore fortement contaminé après la récolte. Quel que soit le cultivar utilisé, toute réduction de la durée végétative diminue l'importance de la génération néoformée (MUGNIERY, 1976). Il semble clair qu'une récolte tardive (fig. 1) contrecarre l'effet de destruction consécutif à l'application des nématicides. Il est clair également que toute récolte hâtive conserve le bénéfice de leurs effets. Cependant, dans les conditions de Guiclan, les récoltes ont eu lieu trop tardivement puisqu'il y a dépendance entre population initiale et taux d'évolution : on n'obtient donc pas une additivité des effets plante-piège et nématicide. Pour obtenir cette efficacité maximale, il faudrait réduire encore la durée de végétation, ce qui entraînerait automatiquement une récolte très faible et non commercialisable. Dans le $1^{\text {er }}$ cas, la diminution globale des populations varie entre 80 et 60 p. 100 . Dans le $2^{\mathrm{e}}$ cas, on devrait obtenir une dimi- nution de $80-90$ p. 100 ou plus s'il y a eu protection chimique.

\section{Conclusion}

L'utilisation de pomme de terre permet de diminuer le contenu larvaire du kyste dans une proportion voisine de $80 \mathrm{p}$. 100 . Si la récolte est effectuée très tôt, la diminution globale de la population est de $80 \mathrm{p} .100 . \mathrm{Si}$ un traitement de contact est appliqué au préalable, on pourra espérer obtenir 90 p. 100 de diminution ; mais dans ce cas, il faut éliminer l'idée d'utiliser un produit endothérapique : celui-ci empêche la pénétration des larves (Den OUDEN, 1971) mais n'a pas ou peu d'influence sur les éclosions.

Dans le cadre de mesures visant l'éradication, il ne semble pas possible, si l'on cultive de la pomme de terre, de le faire autrement qu'en culture piège. Si l'on essaie d'obtenir un quelconque rendement, le risque pratique de multiplication est trop important. Il vaut mieux, dans ce cas, s'en tenir seulement à une culture de plante non hôte à risques pratiquement nuls, hormis celui d'avoir des repousses de pomme de terre (Den OUDEN, 1967 ; HIJINK, 1972).

Considérant les divers résultats obtenus, nous pouvons proposer, comme méthode de lutte concurrente à l'interdiction de la pomme de terre, d'assainir le terrain contaminé par une culture piège de pomme de terre accompagnée d'un traitement de sol avec un nématicide de contact.

\section{Utilisation de 2 cultures pièges et d'un nématicide au cours de 2 années consécutives}

Une parcelle de $3000 \mathrm{~m}^{2}$, à Plouzévédé, interdite à la culture de pomme de terre par suite de la présence de G. pallida, est choisie pour mettre en pratique une méthode d'assainissement rapide. L'opération, échelonnée sur 2 ans, consiste à effectuer 2 cultures pièges de pomme de terre et un traitement nématicide de contact réalisé, soit la $1^{\text {re }}$ année, soit la $2^{\mathrm{e}}$. La destruction des pommes de terre est opérée très tôt pour éviter tout risque de multiplication des nématodes et laisser tout loisir à l'agriculteur d'implanter une autre culture après libération du sol. Le cultivar choisi est tardif pour éliminer tout risque d'ensemencer la parcelle en tubercules fils.

\section{Matériel et méthode}

La parcelle de $3000 \mathrm{~m}^{2}$ est divisée en 2 parties, l'une traitée en 1981, l'autre en 1982. Les traitements ont lieu le jour de la plantation, avec de l'éthoprophos épandu sur la totalité de la surface, à raison de $10 \mathrm{~kg} \mathrm{MA} / \mathrm{ha}$.

La plantation a lieu début avril ; les destructions sont faites les 20 mai 1981 et $1^{\text {er }}$ juin 1982 , à l'aide d'un rotavateur pour la $1^{\mathrm{er}}$ année, et avec une arracheusechargeuse pour la $2^{\mathrm{e}}$.

Les prélèvements de terre sont effectués selon 2 transects courants dans les 2 parties de la parcelle. A partir d'un point fixe, un échantillon de 40 prises élémentaires est prélevé tous les $10 \mathrm{~m}$ sur une surface de $1,5 \mathrm{~m}^{2}$. La totalité de l'échantillon est analysée à l'appareil de Fenwick. Les échantillons de terre sont prélevés en avril 1981, avril 1982 et novembre 1982. 


\section{Résultats}

\section{a) Année 1981}

Il y a dépendance entre population initiale et taux de multiplication (fig. 4). L'évolution du nombre de kystes (fig. 3) confirme qu'il y a eu une légère multiplication

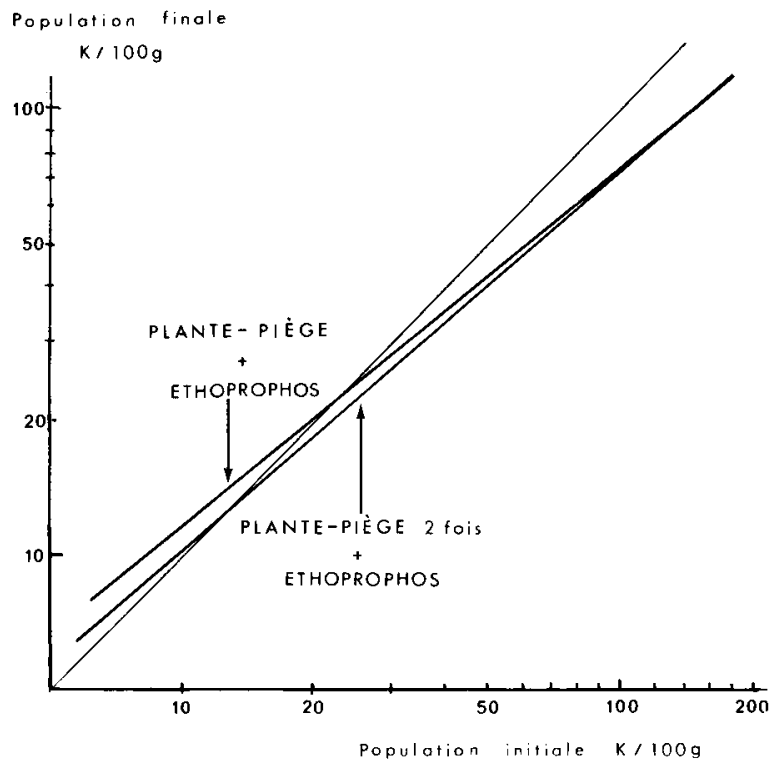

Figure 3

Evolution des kystes de G. pallida après I traitement nématicide et 1 ou 2 ans de plantes pièges.

Ethoprophos : $10 \mathrm{~kg} \mathrm{MA} / \mathrm{ha}$.

Effect of 1 ethoprophos application plus 1 or 2 years of trapcropping on the cyst density of $\mathrm{G}$. pallida.

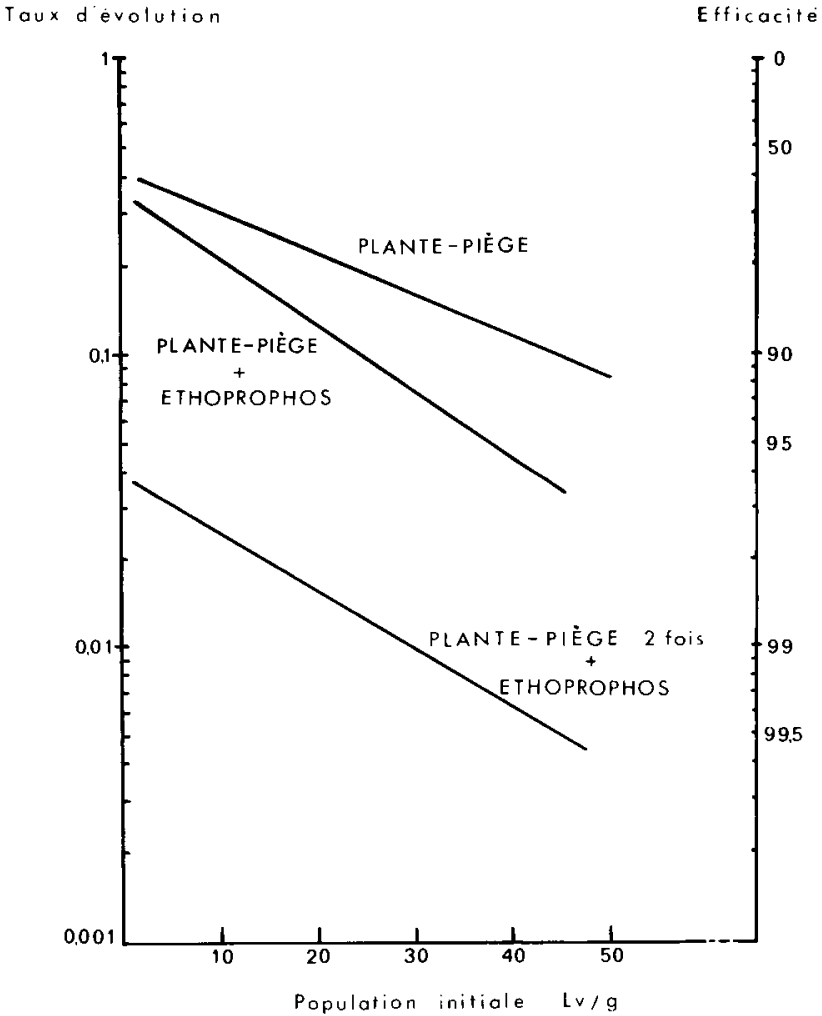

Figure 4

Evolution des populations larvaires de G. pallida après I ou 2 années de plante piège et I traitement nématicide.

Effect of 1 or 2 year trap-cropping plus one ethoprophos application on the density of $\mathrm{G}$. pallida larvae. de nématodes pour les zones très peu infestées. Cette multiplication est due à la présence de repousses de pomme de terre à partir des tubercules-mères au cours de l'été 1981. Mais cette légère multiplication est très faible par rapport à la mortalité engendrée par la pomme de terre piège car, sans protection chimique, la mortalité en larves varie de 70 à 90 p. 100 (moyenne 76 p. 100) ; avec l'éthoprophos, cette mortalité atteint 75 à 96 p. 100 (moyenne 88,4 p. 100).

\section{b) Année 1982}

Le type de destruction effectuée n'a pas entraîné des repousses estivales de pomme de terre. Il y a indépendance totale entre population initiale et taux de multiplication. Il n'y a pas de changement significatif dans le nombre de kystes $(t=1,370$ pour $18 \mathrm{ddl}$ ).

La diminution en larves pour les 2 années 1981 et 1982 varie de 96 à 99,5 p. 100 (moyenne 98,5 p. 100).

\section{Discussion}

L'essai réalisé dans les conditions de la pratique agricole courante conduit, sur 2 ans, à une mortalité générale moyenne des nématodes de plus de 98 p. 100 . Il confirme entièrement l'efficacité de l'emploi de la pomme de terre comme plante piège pour vider les kystes de leur contenu ; cette efficacité se révèle d'un effet absolument comparable à celui d'un traitement nématicide classique réalisé à l'aide d'un fumigant mais difficile à utiliser dans les conditions locales. L'effet aurait pu être encore plus important et dépasser $98 \mathrm{p}$. 100 si le problème des repousses avait pu être maîtrisé dès la $1^{\text {re }}$ année.

Le coût économique de l'opération n'est pas très élevé. Au lieu de plant, on peut semer de la "grenaille " achetée à très bas prix. Les engrais servent à la culture qui suit, maïs fourrager, chou ou haricot. Les coûts incompressibles sont ceux inhérents au tempsmachine pour le semis et la destruction, les traitements herbicide et nématicide.

Les risques de dissémination sont importants en $1^{\text {re }}$ année, très réduits en $2^{\mathrm{e}}$ année et extrêmement faibles par la suite. Enfin, comparée à celle de la méthode passive, l'efficacité de ce procédé de lutte est 10 fois meilleure, puisque passer de 50 à $0,75 \mathrm{lv} / \mathrm{g}$ n'exige que 2 ans, alors qu'il faudrait théoriquement 21 ans (cf. I) sans pomme de terre pour obtenir le même résultat.

\section{CONCLUSION}

En zone de production de plants, la lutte contre le nématode à kystes de la pomme de terre, G. pallida, doit conduire à l'éradication ; elle ne peut pas s'envisager dans un concept de lutte intégrée comme cela est fait en zones maraîchères.

L'abandon total de la culture de pomme de terre, outre le fait qu'il n'élimine pas les problèmes des repousses, comporte le double inconvénient de n'être efficace qu'à très long terme et de laisser subsister des foyers fortement contaminés pendant longtemps. L'existence de ces foyers entraîne de graves risques de contamination pour la région. De plus, les structures agricoles actuelles sont très peu propices à l'abandon de la culture du plant de pomme de terre pendant de très 
longues durées. On peut, à l'inverse, et sans aucun risque, obtenir en un temps très bref des chutes drastiques de populations, ce qui, d'une part, élimine vite le risque de dissémination du parasite, d'autre part, permet d'envisager, dans un avenir pas trop lointain, la réutilisation de ces sols pour la culture des plants.

Il va sans dire que ces mesures ne peuvent s'envisager que dans un plan d'ensemble où figurent la surveillance systématique des parcelles et la rotation. La surveillance systématique sert à déceler de nouveaux foyers et à agir très rapidement avant que les populations du sol ne s'élèvent. La rotation permet de maintenir ces populations à des seuils indécelables et d'éviter que toute introduction accidentelle d'un kyste ne soit à l'origine de nouveaux foyers graves. Cette rotation, qui doit être de 4 années, devra probablement être plus longue dans les parcelles assainies.

Reçu le 15 juin 1983. Accepté le 20 avril 1984

\section{RÉFÉRENCES BIBLIOGRAPHIQUES}

Coolen W. A., d'Herde C. J., 1972. A method for the quantitative extraction of nematodes from plant tissue. Agricultural Research Administration. State Agric. Res. Center., Ghent, 77 p.

Den Ouden H., 1967. The influence of volunteer potato plant in oats on the population density of Heterodera rostochiensis. Nematologica, 13, 325-335.

Den Uuden H.. 1969. Jaaverslae IP(). 13(1)-133.

Den Ouden H., 1971. The effect of some systemic nematicides within potato roots on penetrating or penetrated larvae of Heterodera rostochiensis. Meded. Fac. Landbouw. Rijksuniv., 36, 889-903.

Grainger J., 1964. Factors affecting the control of eelworm diseases. Nematologica, 10, 5-20.

Hijink M. J., 1972. An integrated approach in the control of potato root eelworm. E.P.P.O., Bull. $n^{\circ}$ 7, 41-48.

Jones F. G. W., 1969. Integrated control of the potato cyst nematode. Proc. Sth Br. Insectic. Fungic. Conf., 645, 655.

Mc Kenna L. A., Winslow R. D., 1973. Persistence and infectivity of potato cyst nematode infestations of different ages. Rec. Agric. Res., 21, 37-40.

Mugniery D., 1976. Etablissement d'un modèle de dynamique de population d'Heterodera pallida Stone : applications à un cas pratique de lutte intégrée. Ann. Zool. Ecol. Anim., 8, 315-329.

Mugniery D., 1982a. Influence de l'hôte sur le developpement et l'expression du sexe chez un nématode phytoparasite à déterminisme sexuel épigénique, Globodera pallida Stone. C.R. Acad. Sci. Paris, t. 294, série III, 49-52.

Mugniery D., 1982b. Diversités régionales d'application de lutte intégrée en culture de pomme de terre en fonction de la variabilité des populations de nématodes à kystes. Agronomie, 2, 629-640.

Omidvar A. M., 1962. The nematicidal effects of Tagetes spp. on the final population of Heterodera rostochiensis Woll. Nematologica, 7 , 62-64.
Oostenbrink M., 1950. Het aardappelaaltje (Heterodera rostochiensis Wollenweber) een gevaarlijke parasiet voor de eenzijdige aardappelcultuur. Meded. Plantzk. Dienst, 115, 230 p.

Spears J. F., 1968. The golden nematode handbook. U.S.D.A., Agric. Handbook, $\mathrm{n}^{\circ} 353,81 \mathrm{p}$.

Stelter H., 1970. Eine populationsdynamische Studie über Typ A des Kartoffelnematoden (Heterodera rostochiensis Wollenweber). Nachrbl. at. Pflschut: alenst. Bert., 24, 27-32.

Stone L. E. W., Webley D. P., Lewis S., Evans E. G., 1973. The persistence of potato cyst eelworm (Heterodera pallida Stone) under different non-host regimes. Plant Pathol., 22, 181-183.

Timofeev N. N., Ponin I. Y., 1975. The effect of various orders of anti-nematode rotations of crops with resistant potato varieties on the number of Heterodera rostochiensis. Byul. Vsesoyuznogo Instit. Gel'mintologii im. K. I. Skryabina, 15, 98-101.

Triffitt M. J., 1930. On the bionomics of Heterodera schachtii on potatoes with special reference to the influence of mustard on the escape of the larvae from the cysts. J. Helminth., 8, 19-48.

\section{TEXTES RÉGLEMENTAIRES FRANÇAIS}

Journal Officiel de la République Française, 1972, 1973. Arrêté concernant la lutte contre le nématode doré de la pomme de terre. J.O. 10.02.72 - J.O. 28.01.73.

Règlement technique de la production, du contrôle et de la certification (1978). Tome 2. Certification des plants : plants de pommes de terre, plants de fraisiers, ail et échalote. Ed. GNIS, Paris, 1978, 40 p. 